\title{
ASPECTS Distorts Infarct Volume Measurement
}

$\mathbf{S}$ undaram et $\mathrm{al}^{1}$ reported lucidly on agreements and correlations of ASPECTS for NCCT (manual, automatic) and CTPCBV (manual). But why use ASPECTS, not volume?

Invented as a volume surrogate, ASPECTS takes the form of "content analysis"-a research method to quantify texts and symbols, ${ }^{2}$ wherein ASPECTS unitizes the MCA territory by defining 10 regions and categorizes each unit as having either no or any acute infarction. Measurement is degraded by the unitization's vague definitions and diverse volumes, the binary categorization of so few units, and the bias of "any." ASPECTS promotes interobserver disagreement (masked by "auto-") and scatters markedly away from true volume. It is not excused for individual patient use by mere population correlation. Moreover, ASPECTS tends to advance infarcts by sometimes large margins of error beyond a supposed threshold of risk or futility, denying thrombectomy. A detailed explanation of ASPECTS and its flaws and a quick remediation by manual volumetry using the diameter formula $A B C / 2$ (or a PACS-friendly refinement called $2 S h / 3$ ) are available. $^{3}$

http://dx.doi.org/10.3174/ajnr.A6485
Besides the well-documented $A B C / 2$ and $2 S h / 3$, the software behind any auto-ASPECTS can, in principle, report infarct volumes. If these and other authors skip ASPECTS and use volume, their agreements and correlations might be stronger and their plots less scattered.

Disclosures: Marco C. Pinho-UNRELATED: Consultancy: ABC Medical Education, Comments: On-line educational activities related to MRI.

\section{REFERENCES}

1. Sundaram VK, Goldstein J, Wheelwright D, et al. Automated ASPECTS in acute ischemic stroke: a comparative analysis with CT perfusion. AJNR Am J Neuroradiol 2019;40:2033-38 CrossRef Medline

2. Krippendorff K. Content Analysis: An Introduction to its Methodology, 4th ed. Los Angeles: Sage Publications; 2019

3. Suss RA. ASPECTS, the mismeasure of stroke: a metrological investigation. OSF Preprints 2019 https://doi.org/10.31219/osf.io/ c4tkp. Accessed December 31, 2019

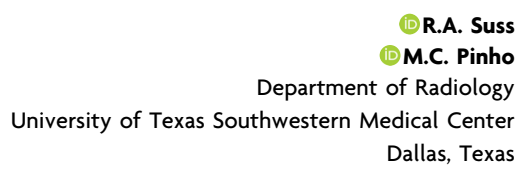

